\title{
The relationship between cognitive style and commitment to the strategic planning in public or- ganizations
}

\section{Bader Enad Alfayez ${ }^{a^{*}}$}

\begin{tabular}{l}
${ }^{a}$ Ministry of Interior, Jordan \\
\hline C H R O N I C L E \\
\hline Article history: \\
Received: February 16, 2020 \\
Received in revised format: \\
March 22 2020 \\
Accepted: March 22, 2020 \\
Available online: \\
March 24, 2020 \\
\hline Keywords: \\
Cognitive style \\
User acceptance model \\
Strategic planning \\
Plan commitment \\
Public organization \\
Jordan \\
\hline
\end{tabular}

\section{A B S T R A C T}

\begin{abstract}
The purpose of this research is to investigate a compilation model of employee individual characteristics towards plan commitment in public organizations. To achieve this, we propose a novel conceptual model that explains the relationship between cognitive style and commitment to strategic planning on Jordan ministry of interior. We then investigate the mediation role of the user acceptance model for both perceived ease of use and usefulness of the strategic planning process among the study variables. Data were collected from 365 employees and senior management at the ministry of interior of Jordan. Data analysis was performed using structural equation modeling (SEM). Our results show that there was a significant relationship between cognitive style and user acceptance model alongside a commitment to strategic planning. In addition, our results show that the perceived usefulness of the strategic planning process mediated the positive relationship between cognitive style and plan commitment.
\end{abstract}

\section{Introduction}

In the continuous turbulence and uncertain environment in the Arab Middle East countries, Jordan has been affected by many internal factors such as economic crisis which has threatened the political instability and external factors such as wars in neighboring countries. In order to cope with these changes, the Ministry of Interior (MI) should incorporate strategic planning (SP) to the structure of its operations in order to make a better projection for the future. SP tool is an important tool for public organizations in turbulent, competitive and uncertain environments. Public organization scholars have defined strategic planning (SP) as "a deliberative, disciplined effort to produce fundamental decisions and actions that shape and guide what an organization (or other entity) is (its identity), what it does (its strategies and actions), and why it does it (mandates, mission, goals, and the creation of public value)" (Bryson 2010, p., 256). SP is operationalized as a systematic process of strategy formulation during which an organization's environment is analyzed and strategic goals are defined (Poister et al., 2013; George et al., 2016). In the light of these rapid changes in the public organization environment, all public organizations have an internal and external environment. The internal environment is associated with the human resource of the organization and the way people undertake work in accordance with the mission of the organization. To a certain extent, the internal environment is controllable and editable through the process of planning and management. The external environment, on the other hand, is not controllable. The senior management of the public organizations have no control over the changes to law, or general economic conditions. However, the senior managers of the organization have a certain degree of control over the way in which the company reacts to changes in its external environment. Organizations experiencing rapidly changing environmental face both high complexity

* Corresponding author.

E-mail address: Bader77.alfayez@gmail.com (B. E. Alfayez) 
and dynamism. This confirms the view that the only constant in this environment is changed. The public organization cannot control these aspects but can respond to change if necessary, and need to develop strategic plans. It became necessary to the perception of future conditions, plans, and the preparation of the necessary actions to address them.

Strategic planning is the key to ensure that our organization is ready to meet the challenges of tomorrow (Aljuhmani, \& Emeagwali, 2017, p., 50). Strategic planning draws a line of conduct based on indicators of what the public organization environment will be in future. Strategic planning helps organizations develop their objectives and clarify the guidelines for the future of the organization for all employees, and also helps to assist in the allocation of resources and the creation of the senior management and the development of skills. Many organizations are seeking to adapt and respond to a changing world and variable which includes many challenges such as global markets, the fierce competition, the lack and the scarcity of resources, the revolution in communications and information technologies, the short life span of the products, and the continuous change of the needs, desires, trends, technology and other. To cope with these events unstable, it requires to follow a high flexibility generated from adaptation of modern management methods to follow the pace of these updates. The Ministry of Interior (MI) faces various types of changes as if other public organizations saw the changes due to intense technological development and changes in the economic environment and politics.

\section{Objective of the Research}

The Jordan Ministry of Interior lacks evidence-based decision-making processes backed up by research. The Ministry of Interior department plays an important part in Jordanian sustainability. It has a crucial supporting role for all major parts in Jordan. As such, understanding employees' individual characteristics in conducting their work is important for policy planners and decision makers in the Jordanian Ministry of Interior.

The main purpose of this research is to identify the level of the cognitive style towards strategic planning and user acceptance of the strategic planning process for both ease of use and usefulness related to plan commitment in the Jordan public organization. It also confirms the importance of strategic planning in the ministry of interior. This paper also intends to examine the impact of individual cognitive style from three different tendencies: knowing style, creating style, and planning style.

This research also intends to determine the nature of the indirect relationship between the cognitive style and plan commitment through user acceptance for both perceived ease of use and usefulness of strategic planning process. It also emphases on increasing the contribution of individual characteristics in commitment towards strategic planning in the public organization through the user acceptance model for both ease of use and usefulness of the strategic planning process.

\section{Research Problem}

The optimal goal of conducting this research is to highlight the most importance of the usage of strategic planning by public organizations, especially in the ministry of interior. Furthermore, building on the call of Bryson et al. (2009), this study adopts a micro-level perspective on strategic planning effectiveness by examining the relationship between cognitive styles of strategic planning, user acceptance of the strategic planning process and employee commitment to strategic plans. By looking at the commitment to strategic plans as a dependent variable, we offer insights into a crucial individual-level process output of strategic planning in public organizations. Earlier research has suggested that employee commitment to the strategic plan is an important driver of successful strategy implementation (Parayitam \& Dooley 2009) because it 'decreases the likelihood of major resistance from those who dislike change' and 'creates a vision or a valued cause that motivates to ensure a successful implementation' (Olson et al., 2007, 203). In other words, commitment to the strategic plan implies that we consider the plan as a set of strategic ideas worth implementing and thus become an important part of the guiding coalition necessary to implement these ideas (Bryson et al., 2009).

\section{Research Questions}

In order to materialize the research problem, this study intends to answer one crucial question: What is the importance of the employee cognitive style of the strategic planning in the plan commitment in Jordanian ministry of interior?

To help answer this question, the following sub-questions are posed for this study:

RQ1: What is the effect of cognitive style on perceived ease of use of the strategic planning process in the Jordan Ministry of Interior?

RQ2: What is the effect of cognitive style on the perceived usefulness of the strategic planning process in the Jordan Ministry of Interior? 
RQ3: What is the effect of cognitive style on plan commitment in the Jordan Ministry of Interior?

RQ4: What is the effect of user acceptance on plan commitment in the Jordan Ministry of Interior?

RQ5: What is the mediating role of user acceptance on the relationship between employee cognitive style and commitment of the strategic planning process in the Jordan Ministry of Interior?

\section{Significance of the Study}

The research provides a substantial and original contribution to the fact that it deals with the ministry of interior occupational stability. Despite a substantial number of researches that have been conducted on the role of the strategic planning in the public organizations in various countries, only a few studies have been conducted in Jordanian ministry of interior; however, the MI, which is one of the most vulnerable public organization in Jordan, especially in the light of the political and economic conditions is pushing the researchers to know how to take benefit of the features provided by employee individual characteristics and its role in employee commitment towards strategic planning process in the ministry of interior.

The more the administration pays attention to the employee's characteristics such as cognitive style, the more it achieves the occupational stability in the organization, that affect its development, since it provides the commitment towards strategic planning process, which is very important for achieving the goals of the public organization. If the strategic planning process is organized on the basis of proper scientific principles, it can play an effective and fundamental role in maximizing employees' commitment to implement the strategic plan. This research focuses on the effect of cognitive style on perceived ease of use and usefulness of the strategic planning process at (MI), while acceptance of the SP process is expected to be related to commitment to implement the strategic plan. The research significance of the cognitive style factors includes: planning style, creating style, and knowing style on the plan commitment at the ministry of interior on Jordan.

\section{Literature and hypotheses}

\section{Cognitive styles, user acceptance and commitment to strategic plan}

Historically, the term cognition refers to the activities of thinking, knowing, and processing information (Armstrong \& Priola 2001). "Cognitive style" has referred to consistencies in an individual's manner of cognitive functioning, particularly in acquiring and processing information (Ausburn \& Ausburn, 1978), and influences how people scan their environment for information, how they interpret this information, and conceive of and deal with task-based problems (Carnabuci \& Diószegi, 2015; Hayes \& Allinson, 1998; Sternberg 2014). Messick (1976) defined cognitive styles as stable attitudes, preferences, or habitual strategies that determine individuals' modes of perception, memory, thought, and problem solving. Similarly, Witkin, Moore, Goodenough, and Cox (1977) characterized cognitive styles as individual differences in the ways people perceive, think, solve problems, learn, and relate to others. Cognitive styles are considered to be relatively permanent, trait-like dimensions, thereby providing stable sources of cognitive diversity in teams, and have become increasingly relevant in organizational research (Carnabuci \& Diószegi, 2015; Kozhevnikov, 2007; Kozhevnikov et al., 2014; Mello \& Rentsch, 2015). While cognitive styles characterize the ways in which individuals represent information, they do not necessarily relate to differences in information or intellectual abilities (Armstrong \& Priola, 2001; Riding \& Cheema, 1991). Hence, individuals with similar intellectual abilities can vary in the way they represent information (i.e., cognitive style). Since team creativity is concerned with the team's ability to see things from different perspectives (Nijstad \& Levine, 2007; Shin \& Zhou, 2007), cognitive styles are key candidates for understanding the impact of the team's cognitive diversity on its creativity, with high cognitive style diversity leading to a greater chance of divergent perspectives and skills in teams, and hence an opportunity for creativity to conceptualize differences in how individuals perceive and interpret information, and to avoid the negative connotations associated with the idea of "cognitive style. More recently, George, Desmidt, Cools, and Prinzie, (2018) use the three-dimensional Cognitive Style Indicator model of Cools and Van den Broek (2007), which distinguishes between creating, knowing and planning cognitive styles in the Flemish municipalities. As George et al. (2018) argued that, 'people scoring high on the creating style tend to make decisions primarily based on intuition or gut feeling (e.g. Cools, Van den Broeck, and Evans 2008, Knockaert et al. 2015). Creators search for renewal, see problems as opportunities, and feel comfortable in situations of uncertainty and freedom' (George et al., 2018, p., 5). People scoring high on the knowing style 'have strong analytical skills, are proficient in logical reasoning and search for accuracy (Cools and Van den Broeck 2007). Knowers like to make informed decisions on the basis of a thorough analysis of facts and logical and rational arguments' (George et al., 2018, p., 5). Finally, people scoring high on the planning style are 'attracted by structure and prefer a well-organized environment (Cools and Van den Broeck 2007). Planners like to make decisions in a structured, systematic way and are concerned with the efficiency of the process' (e.g. Cools, Van den Broeck, and Evans 2008; Knockaert et al. 2015; George et al., 2018, p., 6). We argue that cognitive styles and acceptance of the SP process are individual-level predictors of plan commitment. Specifically, we argue that commitment to strategic plans is contingent on the fit between the preferred way of information-processing (i.e. their cognitive style) and the information-processing characteristics underlying SP processes in public organizations. This is an important research avenue because individual-organizational information-processing fit has been found to play a key role in individuals' acceptance of organizational information-processing systems (Armstrong, Cools, and Sadler-Smith 2012), which, in turn, is 
linked to the behavioral intention to fully adopt this system and its output (Lu, Yu, and Lu 2001). Applied to SP in public organizations, we expect that cognitive style to be related to their acceptance of the SP process while acceptance of the SP process is expected to be related to commitment to implement the strategic plan. Therefore, we proposed that:

H1: A cognitive style is positively related to perceived ease of use of the strategic planning process.

$\mathrm{H} 2$ : A cognitive style is positively related to perceived usefulness of the strategic planning process.

H3: A cognitive style is positively related to commitment to the strategic planning.

H4: Perceived ease of use of the strategic planning process is positively related to commitment to the strategic planning.

H5: Perceived usefulness of the strategic planning process is positively related to commitment to the strategic planning.

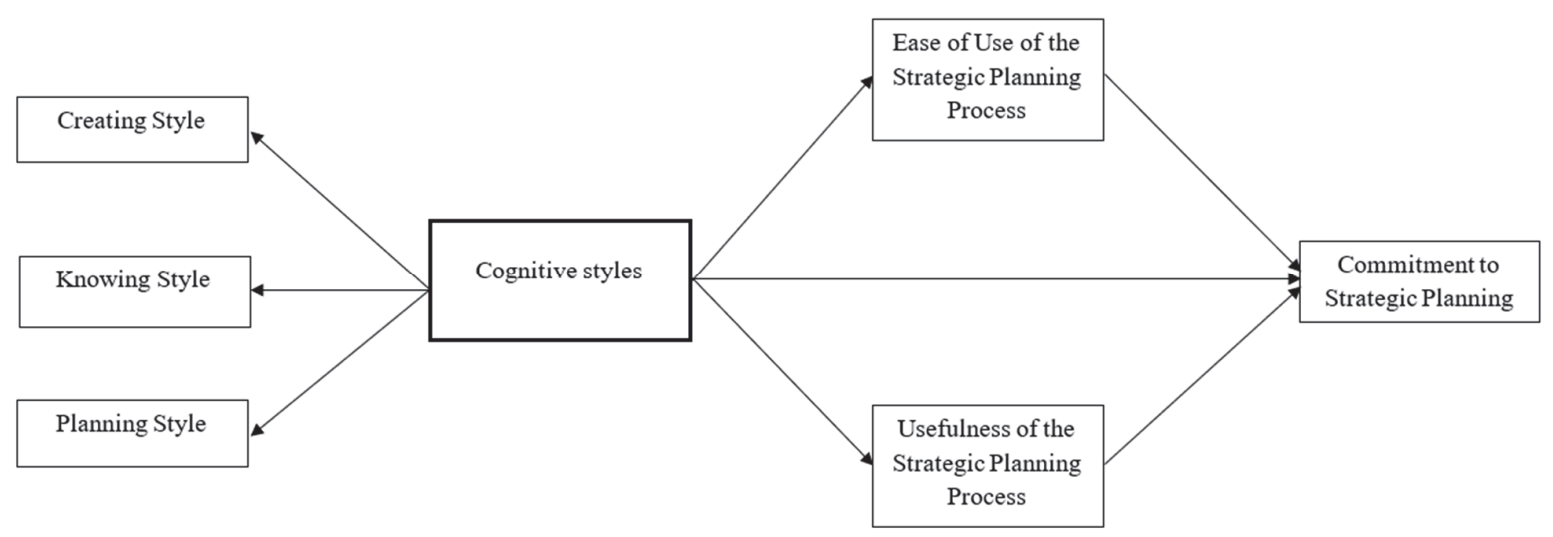

Fig. 1. Conceptual model

\section{Research method}

\section{Sample selection and data collection}

To ensure a relevant level of planning practices, we targeted Ministry of Interior to collect data for this study. The study population consisted of 2226 employees from the capital city of Jordan Amman working at the Head Office. 800 surveys were distributed to the employees in the MI, 391 surveys were returned back and 26 surveys were rejected because of irrelevant responses and/or incomplete questionnaires. The remaining 365 responses (resulting in a response rate of 45.6 percent) were used in our analysis to examine the study hypotheses. In all, 243 respondents were male (66.6 percent) and 122 were female (33.4 percent). Of all, 270 respondents had university degrees (74.0 percent) and 32 respondents held graduate degrees (8.8 percent); 63 respondents provide other degrees (17.3 percent).

According to Podsakoff, Mackenzie, \& Podsakoff, (2012) recommendation, participants were asked to voluntarily participate and they were assured of confidentiality; additionally, a brief information about the research intent was given, and also they were told that there will not be right or wrong answers and that they should answer as honestly as possible. Following Podsakoff, Mackenzie, Lee, \& Podsakoff, (2003, p. 888) "these techniques can reduce people's evaluation apprehension and make them less likely to edit their responses to be more socially desirable, lenient, acquiescent and consistent with how the researcher wants them to respond". And also, this was conducted using a face-to-face (hand-delivered) method to the MI employees, due to "a relatively inexpensive method of collecting high quality, accurate data in a face-to-face manner" (Bush $\&$ Hair, 1985, p. 166). The questions were close-ended multiple choice questions giving respondents a choice from a range of answers based on the 5- point Likert-style rating scale was used to assess each item. This study was controlled by age and strategic planning participation.

To ensure content validity, we collected data from employees and managers familiar with practices of strategic planning in the public organizations. Before completing the questionnaire, respondents were informed of the study's importance as well as the benefits their MI could derive from their participation. Furthermore, interviewers emphasized that all responses would be completely anonymous and confidential and only used for research purposes. The questionnaire was first developed in English, and because the majority of the Jordanian employee mother tong is Arabic language, the research followed backtranslation from English to Arabic. 
The operationalization of our scales was based on existing related research. All scales were five-point Likert scales. To measure the concept of cognitive style, we adopted the scale of Cools and Van den Broeck (2007) with the eighteen-item: seven items for the creating style, four items for the knowing style and seven items for the planning style. A measure of strategic planning commitment was measured with the six-item scale developed by Olson, Parayitam, and Bao (2007). Ease of use and usefulness of the SP process were measured with four items respectively, developed by Hung, Chang, and Yu (2006). The items for both ease of use and usefulness were adapted to the specific context by asking respondents to focus on the ease of use and usefulness of the strategic planning development process underlying the mandated change in planning procedures within MI. Three hundred and sixty-five (365) valid and usable questionnaires for data analysis were used. In order to interpret and summarize data collected, IBM SPSS and AMOS software version 24 were used and to gauge the mediation effect, therefore descriptive statistical techniques were utilized to calculate the means, frequency, percentage and standard deviation of respondents. Given the nature of the proposed conceptual research model developed for this research (Fig. 1), a structural equation modelling (SEM) technique was adopted. As a first step, exploratory factor analysis (EFA) was conducted for this study using SPSS version 23, Maximum Likelihood method was applied, and oblique Promax with Kaiser Normalization was employed. We conclude the results of EFA in the below Table 1. In order to retain the interrelated items to the study constructs 0.4 was taken as a minimum factor loading. Cronbach's were conducting for testing the validity and reliability of our collected data among the study constructs; hence, all the factors were above the acceptable cut-off point of 0.70 .

Table 1

Measurement accuracy assessment

\begin{tabular}{|c|c|c|c|c|c|c|}
\hline Factors & Indicators & $\begin{array}{c}\text { EFA Factor } \\
\text { loading }\end{array}$ & $\begin{array}{l}\text { CFA standardized } \\
\text { loading }\end{array}$ & $\begin{array}{c}\text { Cronbach } \\
\text { Alpha values }\end{array}$ & $\mathrm{CR}$ & AVE \\
\hline \multicolumn{7}{|l|}{ Cognitive Style } \\
\hline \multirow[t]{10}{*}{ Knowing style } & NS1 & .718 & .622 & 0.80 & 0.800 & 0.503 \\
\hline & NS2 & .621 & .751 & & & \\
\hline & NS3 & .611 & .670 & & & \\
\hline & NS4 & .813 & .781 & & & \\
\hline & PS1 & .856 & .834 & 0.85 & 0.859 & 0.505 \\
\hline & PS2 & .642 & .603 & & & \\
\hline & PS3 & .690 & .733 & & & \\
\hline & PS4 & .754 & .701 & & & \\
\hline & PS5 & .690 & .700 & & & \\
\hline & PS6* & .553 & - & & & \\
\hline \multirow[t]{7}{*}{ Planning style } & PS7 & .623 & .674 & & & \\
\hline & CS1* & .538 & - & 0.81 & 0.786 & 0.551 \\
\hline & $\mathrm{CS} 2 *$ & .552 & - & & & \\
\hline & CS3* & .572 & - & & & \\
\hline & CS4* & .589 & - & & & \\
\hline & CS5 & .664 & .707 & & & \\
\hline & CS6 & .784 & .780 & & & \\
\hline Creating style & CS7 & .728 & .739 & & & \\
\hline \multicolumn{7}{|c|}{ User acceptance of strategic planning Dimensions } \\
\hline \multirow[b]{4}{*}{ Usefulness } & UFN1 & .797 & .786 & 0.83 & 0.845 & 0.579 \\
\hline & UFN2 & .855 & .843 & & & \\
\hline & UFN3 & .748 & .765 & & & \\
\hline & UFN4 & .638 & .635 & & & \\
\hline \multirow[b]{4}{*}{ Ease of use } & EOU1 & .701 & .726 & 0.79 & 0.807 & 0.517 \\
\hline & EOU2 & .875 & .876 & & & \\
\hline & EOU3 & .664 & .638 & & & \\
\hline & EOU4 & .618 & .605 & & & \\
\hline \multicolumn{7}{|l|}{ Plan commitment } \\
\hline & PC1 & .752 & .749 & 0.87 & 0.876 & 0.703 \\
\hline & $\mathrm{PC} 2$ & .890 & .870 & & & \\
\hline & PC3 & .874 & .889 & & & \\
\hline & PC4 & .766 & .770 & & & \\
\hline & PC5 & .691 & .735 & & & \\
\hline & PC6 & .664 & .659 & & & \\
\hline
\end{tabular}

Note: Average variance extracted (AVE), Composite reliability (CR), Exploratory factor analysis (EFA), Confirmatory factor analysis (CFA), * Items deleted.

As a next step, a confirmatory factor analysis (CFA) was carried out. Bagozzi and Yi (1988) added that CFA assists scholars and researchers in identifying and determining construct validity (i.e., convergent, discriminant, and nomological validity). 
CFA was conducted on the overall model using Amos version 24. Hence, we used different criteria and threshold in conducting the model fit measures such as Comparative Fit Index (CFI), Square Error of Approximation (RMSEA) And Standardized Root Mean Square Residual (SRMR) adopted from Hu, and Bentler, (1999) cut off points. The below Table 2 summarize the acceptable thresholds and results of a model fit measures. Furthermore, CFA standardized factor loadings $(\lambda)$ was checked for testing the convergent validity. Furthermore, Construct Reliability (CR) and Average Variance Extracted (AVE) was checked also based on the CFA model measurement. The above Table 1 summarized the results of standardized factor loading, CR and AVE. The values of CR were above the acceptable threshold of 0.70 (Fornell, \& Larcker, 1981). And, the values of standardized factor loading were above the acceptable cut-off point of 0.50 . Finally, the values of AVE were acceding the acceptable cut-off points of 0.50 (Fornell, \& Larcker, 1981). These results seemed to be satisfactory for a constructs reliability and convergent validity. The below Table 3 represent the correlation matrix among study constructs.

Table 2

Model fit measures

\begin{tabular}{cccc}
\hline Measures & Recommended criteria & Measurement model & Path model \\
\hline CMIN & - & 506.446 & 311.000 \\
DF & - & 1.628 & 5.768 \\
X2/d.f. & $<3$ & 0.949 & 1.354 \\
CFI & $>0.9$ & 0.055 & 0.995 \\
SRMR & $<0.08$ & 0.042 & 0.033 \\
RMSEA & $<0.08$ & 0.985 & 0.031 \\
PClose & $>0.05$ & 0.655 & \\
\hline
\end{tabular}

Table 3

Means, standard deviations, and correlations matrix among the study construct

\begin{tabular}{llllllll}
\hline Factors & Mean & St. Deviation & 1 & 2 & 3 & 4 & 5 \\
\hline Planning style & 2.50 & 0.834 & 0.711 & & & & \\
Creating style & 3.17 & 0.651 & 0.014 & 0.743 & & & \\
Usefulness & 2.86 & 0.441 & $0.234^{* * *}$ & 0.080 & 0.761 & -0.071 & 0.719 \\
Ease of use & 1.53 & 0.521 & $-0.123^{*}$ & -0.079 & $-0.150^{*}$ & 0.709 \\
Knowing style & 2.23 & 0.480 & $0.556^{* * *}$ & -0.057 & -0.035 & $-0.112 \dagger$ & 0.495 \\
Plan commitment & 2.36 & 0.525 & 0.322 & -0.109 & -0.723 & \\
\hline
\end{tabular}

\section{Structural model and hypotheses testing}

Structural equation modelling was used for testing the research hypotheses based on Amos version 24 statistics program in order to interpret and estimate the research results. The below Fig. 2 with the below Table 4 represent the structural model and the research results. As a first step in conducting a structural model is looking for a good model fit measure. The above Table 3 showed that the results of a model fit measures. Our research model met all the criteria for a good model fit (Hu, \& Bentler, 1999).

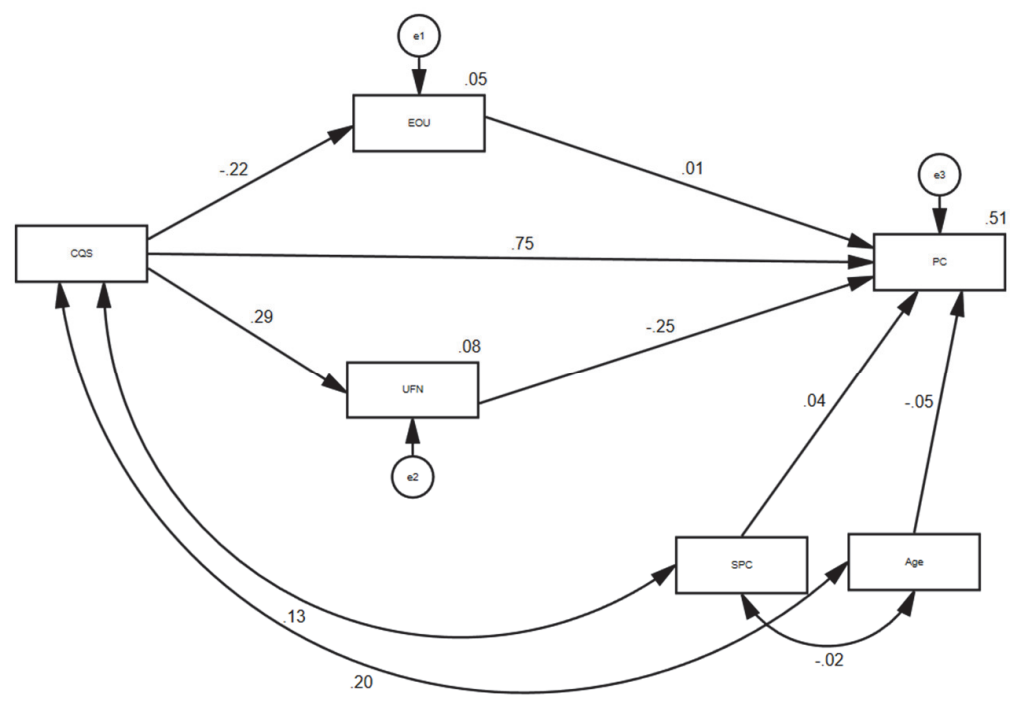

Fig. 2. Path model results 
In this study, a scale for measuring the cognitive style was proposed first. Through exploratory and confirmatory factor analyses, we identified three dimensions of cognitive style, including knowing style, planning style, and creating style. The final instrument showed adequate reliability and validity. Further, we empirically investigated how the dimensions of the cognitive style as a second-order construct and user acceptance dimensions (ease of use and usefulness of the strategic planning process) affecting employee commitment toward strategic plans in the context of MI in Jordan.

Table 4

Direct effect results

\begin{tabular}{|c|c|c|c|c|c|c|c|c|c|}
\hline & Direct Path & & Hypothesis & $\begin{array}{c}\text { Unstandardized } \\
\text { Estimate }\end{array}$ & $\begin{array}{l}\text { Standardized } \\
\text { Estimate }\end{array}$ & S.E. & C.R. & $\mathrm{P}$ & Results \\
\hline Cognitive style & $\rightarrow$ & Ease of use & $\mathrm{H} 1$ & -.215 & -.218 & .050 & -4.266 & $* * *$ & Supported \\
\hline Cognitive style & $\rightarrow$ & Usefulness & $\mathrm{H} 2$ & .365 & .285 & .064 & 5.678 & $* * *$ & Supported \\
\hline Cognitive style & $\rightarrow$ & Plan commitment & H3 & .810 & .750 & .043 & 18.712 & $* * *$ & Supported \\
\hline Ease of use & $\rightarrow$ & Plan commitment & $\mathrm{H} 4$ & .011 & .010 & .041 & .274 & .784 & $\begin{array}{l}\text { Not Sup- } \\
\text { ported }\end{array}$ \\
\hline Usefulness & $\rightarrow$ & Plan commitment & H5 & -.209 & -.248 & .032 & -6.499 & $* * *$ & Supported \\
\hline
\end{tabular}

Table 5

Indirect effect results

\begin{tabular}{cccccc}
\hline Indirect Path & Unstandardized Estimate & Lower & Upper & P-Value & Standardized Estimate \\
\hline $\mathrm{CQS} \rightarrow \mathrm{UFN} \rightarrow \mathrm{PC}$ & -0.076 & -0.108 & -0.053 & 0.001 & $-0.071^{* * *}$ \\
$\mathrm{CQS} \rightarrow \mathrm{EOU} \rightarrow \mathrm{PC}$ & -0.002 & -0.017 & 0.012 & 0.762 & -0.002 \\
\hline
\end{tabular}

According to Table 4, H1 which was hypothesized that cognitive style has a negative direct effect on perceived ease of use of the SP process $(\beta=-0.218, p<0.001)$ is accepted. This result implied negative sign and did not support our prediction that cognitive style has a positive effect on perceived ease of use of the SP process. The result of H2 $(\beta=0.285, \mathrm{p}<0.001)$ indicated that cognitive style has a positive direct effect on perceived usefulness of the SP process was accepted. Pertaining to $\mathrm{H} 3$ predicting a positive impact of cognitive style on plan commitment $(\beta=0.750, \mathrm{p}<0.001)$. Therefore, $\mathrm{H} 3$ was accepted. $\mathrm{H} 4$ the result showed that there is no direct impact of perceived ease of use of the SP process on plan commitment $(\beta=0.010$, $\mathrm{p}<0.784)$ was rejected. The result of $\mathrm{H} 5(\beta=-0.248, \mathrm{p}<0.001)$ indicated that perceived usefulness of the SP process has a significant impact on plan commitment. This result implied negative sign and did not support our prediction that perceived usefulness of the SP process has a positive effect on plan commitment. Therefore, H5 was accepted negatively.

\section{Further analysis: mediating effect of user acceptance}

In order to test the mediation effects, this study employed the bootstrapping procedure and identified whether the direct relationship between cognitive style and plan commitment through perceived ease of use and usefulness of the SP process are statistically significant. Even though the research model (see Fig. 1) suggests two possible mediation effects, the direct effect results (Table 4) confirm the direct effect of cognitive style on plan commitment is statistically significant. In other words, when the researcher wants to test the mediation effect, they should first test the main effect between the independent variable and dependent variable (Baron \& Kenny, 1986; Awang, 2015). When the mediator impact of user acceptance for both ease of use and usefulness of strategic planning process included in the research model, the direct relationship between cognitive style and plan commitment would be changed. If the direct impact diminishes but remains statistically significant, the mediation effects in this situation called "partial mediation". However, if the direct effect diminishes but becomes statistically insignificant, then the mediation effect in this situation called "full mediation" (Awang, Z. 2015). Table 5 revealed that, as was expected a statistically significant indirect impact of cognitive style on plan commitment through perceived usefulness of the SP.

The results of the indirect effect $(\beta=-0.071, p<0.001)$ indicate that perceived usefulness of the strategic planning process partially mediate the relationship between cognitive style and plan commitment. It can be concluded that perceived usefulness of the strategic planning has a partial mediation effect in the relationship between cognitive style and commitment to strategic planning. These conclusions suggest that a high employee cognitive style towards strategic planning in the ministry of interior leads to lower perceived usefulness of the strategic planning is negatively related to commitment to the strategic plan. These results emphasize the important role of the perceived usefulness of the strategic planning in explaining the nature of the relationship between cognitive style and plan commitment. Therefore, this variable plays a vital role in the development and enhancement of employee commitment towards strategic planning within the public organization than the perceived ease of use of the strategic planning process which has no mediation effect in the relationship between cognitive style and plan commitment. 


\section{Discussion and conclusion}

The purpose of this research was to investigate a comprehensive model of plan commitment in the public organizations of Jordan. Building on the individual characteristics of the cognitive style (knowing style, planning style, and creating style) and user acceptance theories on employee commitment towards strategic planning, this research has extended prior research frameworks by empirically investigating how cognitive style as a second order construct and user acceptance model for both ease of use and usefulness of the strategic planning process affecting plan commitment, and then we examined the mediator effect of the user acceptance model in order to strengthen the relationship between cognitive style and plan commitment in the context of Jordanian public organizations in general and MI in particular. The research findings were as follows:

Looking at the influence of individual cognitive style on their acceptance of strategic planning, we found that a cognitive style is more likely to find the strategic planning process for both easy to use and useful. These findings for the cognitive style support our hypothesized direct relations (hypothesis 1 and hypothesis 2). In addition, this study confirmed that cognitive style was positively and significantly related to plan commitment in the public organizations (hypothesis 3 ). This finding is relevant for public organizations because previous research illustrated that the individual characteristics of cognitive style was positively related to commitment strategic planning in the public organization in general (George \& Desmidt 2014; Boyne et al., 2002) and creating style in particular (George et al., 2018).

The results of the relationship between user acceptance for both ease of use and usefulness of the strategic planning process and commitment to strategic planning in the public organization was only limited to the perceived usefulness of the strategic planning and does not apply to the perceived ease of use (hypothesis 4). This is because this result could lie in the specific context of strategic planning in the public organizations (George et al., 2018).

Consistent with previous studies, the findings of the structural model confirmed that the importance of user acceptance is illustrated through the positive relationship between perceived usefulness of the SP process and their commitment to the strategic plan (hypothesis 5). This finding is relevant for public organizations because previous research illustrated that the adoption of SP requires time, technical expertise and organizational resources and SP processes are inherently difficult to adopt and execute (George et al., 2018).

Finally, we found evidence for the mediating effects of perceived usefulness of the strategic planning process in the relationship between cognitive style and plan commitment in the public organizations are confirmed and in line with the findings of previous studies (George et al., 2018). The findings of this study contribute to the current body of knowledge in the context of public organizations in several ways. The results provide a comprehensive understanding of the determinates of plan commitment. Especially, this research provides strong evidence of the important roles of user acceptance model in general and the perceived usefulness of the strategic planning process in particular as a mediator role in the relationship between cognitive style and plan commitment. Furthermore, the research enhances our understanding of the factors underlying commitment to strategic plans in the public organizations by providing evidence from ministry of interior in Jordan.

\section{References}

Aljuhmani, H. Y., \& Emeagwali, O. L. (2017). The roles of strategic planning in organizational crisis management: The case of Jordanian banking sector. International Review of Management and Marketing, 7(3), 50-60.

Armstrong, S. J., \& Priola, V. (2001). Individual differences in cognitive style and their effects on task and social orientations of self-managed work teams. Small Group Research, 32(3), 283-312.

Armstrong, S. J., Cools, E., \& Sadler-Smith, E. (2012). Role of cognitive styles in business and management: Reviewing 40 years of research. International Journal of Management Reviews, 14(3), 238-262.

Ausburn, L. J., \& Ausburn, F. B. (1978). Cognitive styles: Some information and implications for instructional design. Ectj, 26(4), 337-354.

Awang, Z. (2015). SEM made simple: A gentle approach to learning Structural Equation Modeling. MPWS Rich Publication.

Bagozzi, R. P., \& Yi, Y. (1988). On the evaluation of structural equation models. Journal of the Academy of Marketing Science, 16(1), 74-94.

Baron, R. M., \& Kenny, D. A. (1986). The moderator-mediator variable distinction in social psychological research: Conceptual, strategic, and statistical considerations. Journal of Personality and Social Psychology, 51(6), 1173.

Boyne, G., Gould-Williams, J., Law, J., \& Walker, R. (2002). Plans, performance information and accountability: the case of best value. Public Administration, 80(4), 691-710.

Bryson, J. M. (2010). The future of public and nonprofit strategic planning in the United States. Public Administration Review, 70, s255-s267.

Bryson, J. M., Crosby, B. C., \& Bryson, J. K. (2009). Understanding strategic planning and the formulation and implementation of strategic plans as a way of knowing: The contributions of actor-network theory. International Public Management Journal, 12(2), 172-207. 
Bush, A. J., \& Hair Jr, J. F. (1985). An assessment of the mall intercept as a data collection method. Journal of Marketing Research, 22(2), 158-167.

Carnabuci, G., \& Diószegi, B. (2015). Social networks, cognitive style, and innovative performance: A contingency perspective. Academy of Management Journal, 58(3), 881-905.

Cools, E., \& Van den Broeck, H. (2007). Development and validation of the Cognitive Style Indicator. The Journal of psychology, 141(4), 359-387.

Evans, C., Graff, M., Cools, E., \& Van Den Broeck, H. (2008). Cognitive styles and managerial behaviour: a qualitative study. Education+ Training.

Fornell, C., \& Larcker, D. F. (1981). Evaluating structural equation models with unobservable variables and measurement error. Journal of Marketing Research, 18(1), 39-50.

George, B., \& Desmidt, S. (2014). 10 A State of Research on Strategic Management in the Public Sector. Strategic management in public organizations: European Practices and Perspectives, 151.

George, B., Desmidt, S., \& De Moyer, J. (2016). Strategic decision quality in Flemish municipalities. Public Money \& Management, 36(5), 317-324.

George, B., Desmidt, S., Cools, E., \& Prinzie, A. (2018). Cognitive styles, user acceptance and commitment to strategic plans in public organizations: an empirical analysis. Public Management Review, 20(3), 340-359.

Hayes, J., \& Allinson, C. W. (1998). Cognitive style and the theory and practice of individual and collective learning in organizations. Human Relations, 51(7), 847-871.

Hu, L. T., \& Bentler, P. M. (1999). Cutoff criteria for fit indexes in covariance structure analysis: Conventional criteria versus new alternatives. Structural Equation Modeling: A Multidisciplinary Journal, 6(1), 1-55.

Hung, S. Y., Chang, C. M., \& Yu, T. J. (2006). Determinants of user acceptance of the e-Government services: The case of online tax filing and payment system. Government Information Quarterly, 23(1), 97-122.

Knockaert, M., Der Foo, M., Erikson, T., \& Cools, E. (2015). Growth intentions among research scientists: A cognitive style perspective. Technovation, 38, 64-74.

Kozhevnikov, M. (2007). Cognitive styles in the context of modern psychology: Toward an integrated framework of cognitive style. Psychological Bulletin, 133(3), 464.

Kozhevnikov, M., Evans, C., \& Kosslyn, S. M. (2014). Cognitive style as environmentally sensitive individual differences in cognition: A modern synthesis and applications in education, business, and management. Psychological Science in the Public Interest, 15(1), 3-33.

Lu, H. P., Yu, H. J., \& Lu, S. S. (2001). The effects of cognitive style and model type on DSS acceptance: An empirical study. European Journal of Operational Research, 131(3), 649-663.

Mello, A. L., \& Rentsch, J. R. (2015). Cognitive diversity in teams: A multidisciplinary review. Small Group Research, 46(6), 623-658.

Messick, S. (1976). Individuality in learning. Jossey-Bass.

Nijstad, B. A., \& Levine, J. M. (2007). 10 Group creativity and the stages of creative problem solving. The Scope of Social Psychology, 159.

Olson, B. J., Parayitam, S., \& Bao, Y. (2007). Strategic decision making: The effects of cognitive diversity, conflict, and trust on decision outcomes. Journal of Management, 33(2), 196-222.

Parayitam, S., \& Dooley, R. S. (2009). The interplay between cognitive-and affective conflict and cognition-and affect-based trust in influencing decision outcomes. Journal of Business Research, 62(8), 789-796.

Podsakoff, P. M., MacKenzie, S. B., \& Podsakoff, N. P. (2012). Sources of method bias in social science research and recommendations on how to control it. Annual Review of Psychology, 63, 539-569.

Podsakoff, P. M., MacKenzie, S. B., Lee, J. Y., \& Podsakoff, N. P. (2003). Common method biases in behavioral research: a critical review of the literature and recommended remedies. Journal of Applied Psychology, 88(5), 879.

Poister, T. H., Pasha, O. Q., \& Edwards, L. H. (2013). Does performance management lead to better outcomes? Evidence from the US public transit industry. Public Administration Review, 73(4), 625-636.

Riding, R., \& Cheema, I. (1991). Cognitive styles - an overview and integration. Educational Psychology, 11(3-4), 193-215.

Shin, S. J., \& Zhou, J. (2007). When is educational specialization heterogeneity related to creativity in research and development teams? Transformational leadership as a moderator. Journal of Applied Psychology, 92(6), 1709.

Sternberg, R. J. (2014). Introduction: Adopted at last!. Psychological Science in the Public Interest.

Witkin, H. A., Moore, C. A., Goodenough, D. R., \& Cox, P. W. (1977). Educational implications of cognitive styles. Review of Educational Research, 47(1), 1-64. 
(C) 2020 by the authors; licensee Growing Science, Canada. This is an open access article distributed under the terms and conditions of the Creative Commons Attribution (CC-BY) license (http://creativecommons.org/licenses/by/4.0/). 